University of Nebraska - Lincoln

DigitalCommons@University of Nebraska - Lincoln

Faculty Publications - Chemistry Department Published Research-Department of Chemistry

8-6-2007

\title{
Synthesis and Structural Characterization of Two Five Coordinate Aluminum Alkyl and Bis(Trimethylsilyl)Amino Complexes Bearing Acyclic Tetradentate Schiff Bases
}

\author{
C. R. Wade \\ University of Nebraska - Lincoln \\ B. J. Lamprecht \\ University of Nebraska - Lincoln \\ V. W. Day \\ University of Kansas, 1251 Wescoe Hall Drive, Lawrence, KS \\ John A. Belot \\ University of Nebraska - Lincoln, jbelot2@unl.edu
}

Follow this and additional works at: https://digitalcommons.unl.edu/chemfacpub

Part of the Chemistry Commons

Wade, C. R.; Lamprecht, B. J.; Day, V. W.; and Belot, John A., "Synthesis and Structural Characterization of Two Five Coordinate Aluminum Alkyl and Bis(Trimethylsilyl)Amino Complexes Bearing Acyclic Tetradentate Schiff Bases" (2007). Faculty Publications -- Chemistry Department. 24.

https://digitalcommons.unl.edu/chemfacpub/24

This Article is brought to you for free and open access by the Published Research - Department of Chemistry at DigitalCommons@University of Nebraska - Lincoln. It has been accepted for inclusion in Faculty Publications -Chemistry Department by an authorized administrator of DigitalCommons@University of Nebraska - Lincoln. 
Published in Polyhedron 26:13 (August 6, 2007), pp. 3286-3290; doi: 10.1016/j.poly.2007.03.008

Copyright $\odot 2007$ Elsevier Ltd. Used by permission. http://www.elsevier.com/locate/poly

Submitted October 30, 2006; accepted March 3, 2007; published online March 15, 2007.

\title{
Synthesis and structural characterization of two five coordinate aluminum alkyl and bis(trimethylsilyl)amino complexes bearing acyclic tetradentate Schiff bases
}

\author{
C. R. Wade, ${ }^{\text {a B. J. Lamprecht, }}{ }^{\text {a }}$ V. W. Day, ${ }^{b}$ and J. A. Belot ${ }^{a}$ \\ a Department of Chemistry and Center for Materials Research Analysis, \\ University of Nebraska-Lincoln, Lincoln, NE 68588-0304, USA \\ ${ }^{b}$ Department of Chemistry, University of Kansas, \\ 1251 Wescoe Hall Drive, Lawrence, KS 66045, USA \\ Corresponding author - J. A. Belot, tel 402 472-5666, fax 402 472-9402, email jbelot2@unl.edu
}

\begin{abstract}
Two acyclic Schiff-base ligands, bis-5,5'-(1,3-propanediyldiimino)-2,2-dimethyl-4-hexene-3-one and bis-5,5'-(1,3-ethanediyldiimino)-2,2-dimethyl-4-hexene-3-one, were used to complex homoleptic triethylaluminum and tris[bis(trimethylsilyl)amino]alu minum, respectively. The acid-base reactions proceeded in excellent yields with elimination of ethane or bis(trimethylsilyl)amine during in situ deprotonation of the protio Schiff-base. The colorless aluminum complexes crystallized from $n$-pentane and were characterized by standard methods including single crystal X-ray diffraction. Polymerization of racemic lactide, with addition of alcohol, yielded PLA with narrow polydispersities but low molecular weights.
\end{abstract}

Keywords: aluminum, Schiff-base, x-ray, catalysis, polymerization

\section{Introduction}

Schiff-bases (SB) constitute one of the oldest chelator classes in inorganic chemistry and continue to receive considerable attention. One active research area is the binding of Group 13 elements to SBs affording 5-coordinate species where bonding occurs through classical $\mathrm{N}_{2} \mathrm{O}_{2}$ ligation [1]. Analogously, we have been interested in assessing the extent to which steric factors of the Schiff-base, as well as those of other ligands bound to the metal (typically monodentate monoanions) can influence catalysis [1]. Previously, our focus concentrated on modifying the frontal, "saturated" SB steric bulk, and now we sought to include direct comparisons of linker length (Figure 1). Indeed, much of the resurgence associated with similar complexes is attributable to their activity in numerous catalytic cycles and relativity low envirotoxicity $\left(\right.$ for $\mathrm{Al}^{3+}$ ) [2]. Particularly relevant is the use of aluminum centers with aromatic Salen-type ligands for the polymerization of biodegradable and biocom- patible polymers, such as those derived from lactones, lactides, carbon dioxide and epoxides, and other renewable resources [3], [4-7]. Recent reviews by Atwood [1] and Lewinski and Zachara [8] serve as testament to the burgeoning activity in this area. In our hands we, for the first time, wanted to evaluate "saturated" SB Al ${ }^{3+}$ complexes for the polymerization of racemic lactide. The advantages of these complexes would be the lack of aromaticity and tunable peripheral steric bulk, both precluding the possibility of oligomerization in the solution and solid-state species [9].

Our secondary interest in these Group 13 complexes stems from their utility as benchmarks to isoelectronic five-coordinate rare earth Schiff-base complexes [9]. The present study was also designed to compare $\mathrm{Al}^{3+}$ structural features and activities with those of these heavier congeners. To this end, we synthesized a new ligand (bis-5,5'-(1,3-ethanediyldiimino)-2,2-dimethyl-4-hexene-3-one, (1) and two, five-coordinate metal complexes (2 and 3) exploiting in situ deprotonation reactions. 

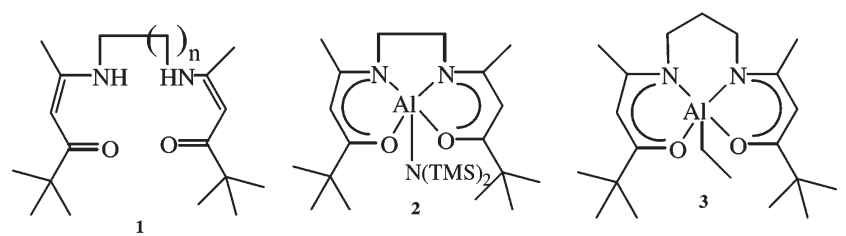

Figure 1. "Saturated" Schiff-base ligand (1) and the two $\mathrm{Al}^{3+}$ complexes (2 and 3$)$.

Marked structural differences exist between $\mathbf{2}$ and $\mathbf{3}$ and amongst their square pyramidal rare earth counterparts. The $\mathrm{Al}^{3+}$ coordination polyhedron is rigorously trigonal bipyramidal in $\mathbf{3}$ and distorted trigonal pyramidal in 2; this difference is due at least in part to the Schiff-base ethylene spacer in $\mathbf{2}$ that is less flexible than the propylene spacer in 3.

\section{Experimental}

\subsection{Materials and methods}

Standard Schlenk techniques and a Vacuum Atmospheres $\mathrm{N}_{2}$-filled glovebox were used throughout the isolation and handling of all aluminum complexes. 1,2-diaminoethane (Acros), absolute ethanol (EtOH, Pharmco), $\mathrm{Et}_{3} \mathrm{Al}$ solution (Aldrich) and benzene $\left(\mathrm{C}_{6} \mathrm{H}_{6}\right)$ were used as received whereas alkali earth bis(trimethy 1silyl)amides (Gelest) and rac-lactide were first purified by double sublimation at $\sim 10^{-5}$ Torr. 2,2-Dimethyl-3,5hexanedione [10] and bis-5,5'-(1,3-propanediyldiimino)2,2-dimethyl-4-hexene-3-one [9] were synthesized using literature methods. Toluene $\left(\mathrm{C}_{7} \mathrm{H}_{8}\right)$ and deuterated benzene $\left(\mathrm{C}_{6} \mathrm{D}_{6}\right)$ with sodium metal and pentane $\left(\mathrm{C}_{5} \mathrm{H}_{12}\right.$ $\mathrm{CaH}_{2}$ ) were dried and distilled immediately before use. Polymerization reactions followed Nomura's procedure [6], and dry $\mathrm{MeOH}$ was added to activate the catalysts. ${ }^{1} \mathrm{H}$ and ${ }^{13} \mathrm{C}$ NMR were recorded on a GE $300 \mathrm{MHz}\left({ }^{1} \mathrm{H}\right)$ and processed using NUTS software. The solid-state molecular structures of $\mathbf{2}$ and $\mathbf{3}$ were determined by single crystal X-ray diffraction at Wake Forest University (Table 1) and elemental analyses were performed at Midwest Microlabs (Indianapolis, IN). Melting points were determined using a modified Mel-Temp II with digital thermocouple readouts and are uncorrected.

\subsection{Synthesis of bis-5,5'-(1,3-ethanediyldiimino)-2,2-di- methyl-4-hexene-3-one (1)}

Under ambient conditions, to a $250 \mathrm{~mL} 24 / 40$ 1-neck round bottom flask charged with $50 \mathrm{~mL} \mathrm{EtOH}$ and $17.3 \mathrm{~g}$ (122 mmol) 2,2-dimethyl-3,5-hexanedione was

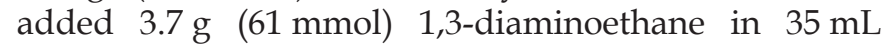
EtOH dropwise over 30 minutes. Following this, a condenser replaced the $125 \mathrm{~mL}$ addition funnel and the reaction heated at reflux overnight, after which time it was diluted with $100 \mathrm{~mL} d \mathrm{H}_{2} \mathrm{O}$ and extracted twice with $30 \mathrm{~mL} \mathrm{Et}_{2} \mathrm{O}$. The organics were washed with $4 \times 20 \mathrm{~mL}$ $\mathrm{H}_{2} \mathrm{O}$, dried over $\mathrm{Na}_{2} \mathrm{SO}_{4}$, filtered, and removed in vacuo yielding a dull-yellow wax. This crude product was subjected to a $\mathrm{C}_{6} \mathrm{H}_{6}$ azeotrope and recrystallized from $\mathrm{C}_{7} \mathrm{H}_{16}$ affording colorless crystals of $\mathbf{1}$ in unoptimized yields between $60 \%$ and $80 \% ;{ }^{1} \mathrm{H}$ NMR $\left(\delta, \mathrm{CDCl}_{3}\right): 1.21(\mathrm{~s}, 18 \mathrm{H})$, $1.92(\mathrm{~m}, 6 \mathrm{H}), 3.40(\mathrm{~m}, 4 \mathrm{H}), 5.15(\mathrm{~s}, 2 \mathrm{H}), 11.1(\mathrm{~b}, 2 \mathrm{H}) ;{ }^{13} \mathrm{C}$ NMR $\left(\delta, \mathrm{CDCl}_{3}\right)$ : 19.3, 28.0, 41.5, 43.6, 91.5, 163.8, 204.7; Anal. Calc. for $\mathrm{C}_{18} \mathrm{H}_{32} \mathrm{~N}_{2} \mathrm{O}_{2}$ : C, 70.09; H, 10.46; N, 9.08. Found $\mathrm{C}, 69.85 ; \mathrm{H}, 10.06$; N, 9.03\%.

\subsection{Bis-5,5'-(1,3-ethanediyldiimino)-2,2-dimethyl-4-hexene- 3-onato aluminum bis(trimethylsilyl)amino (2)}

Forty milliliters of $\mathrm{C}_{7} \mathrm{H}_{16}$ dissolved $0.316 \mathrm{~g}(1.02 \mathrm{mmol})$ anhydrous 1 and simultaneously, in a $100 \mathrm{~mL}$, 1-neck round bottom flask $0.528 \mathrm{~g}(1.04 \mathrm{mmol}) \mathrm{Al}\left[\mathrm{N}(\mathrm{TMS})_{2}\right]_{3}$ [11] was dissolved in $10 \mathrm{~mL} \mathrm{C}_{7} \mathrm{H}_{16}$. The ligand solution was then added to the flask containing $\mathrm{Al}\left[\mathrm{N}(\mathrm{TMS})_{2}\right]_{3}$ via syringe in one portion and the reaction stirred at reflux overnight, after which time the solvent was removed in vacuo. The white solids were then recrystallized from minimal $\mathrm{C}_{5} \mathrm{H}_{12}$ in a $-20^{\circ} \mathrm{C}$ freezer for 2 days to afford colorless crystals. Yield 92\%; m.p. $141-143{ }^{\circ} \mathrm{C}$ (dec.); ${ }^{1} \mathrm{H}$ $\operatorname{NMR}\left(\mathrm{C}_{6} \mathrm{D}_{6}\right): \delta 0.39(\mathrm{~s}, 9 \mathrm{H}) ; 1.29(\mathrm{~s}, 9 \mathrm{H}) ; 1.35(\mathrm{~s}, 3 \mathrm{H}) ; 2.66$ $(\mathrm{m}, 1 \mathrm{H}) ; 3.28(\mathrm{~m}, 1 \mathrm{H}) ; 5.21(\mathrm{~s}, 1 \mathrm{H}) ;{ }^{13} \mathrm{C}$ NMR $\left(\mathrm{C}_{6} \mathrm{D}_{6}\right): \delta$ 5.5; 21.2; 28.6; 39.1; 45.7; 95.4; 171.3; 188.8; Anal. Calc. for $\mathrm{C}_{24} \mathrm{H}_{48} \mathrm{~N}_{3} \mathrm{O}_{2} \mathrm{Si}_{2} \mathrm{Al}$ : C, 58.37; H, 9.80; N, 8.51. Found: C, $56.88 ; \mathrm{H}, 9.23 ; \mathrm{N}, 8.01 \%$.

\subsection{Bis-5,5'-(1,3-propanediyldiimino)-2,2-dimethyl-4-hex- ene-3-onato ethylaluminum (3)}

$4.75 \mathrm{~mL}$ of $1.0 \mathrm{M} \mathrm{AlEt}_{3}$ (4.75 mmol) was slowly added, via a syringe, to a $100 \mathrm{~mL}$ Schlenk flask containing a solution of $1.54 \mathrm{~g}(4.77 \mathrm{mmol}) \mathbf{1}$ in $35 \mathrm{~mL}$ dry $\mathrm{C}_{7} \mathrm{H}_{8}$. Addition of $\mathrm{AlEt}_{3}$ caused the reaction to become yellow and evolve ethane gas. After stirring ( $\sim 5 \mathrm{~min})$ the solution returned to colorless. The reaction was heated at reflux overnight and solvent removed in vacuo to afford an off-white solid. The product crystallized from $\mathrm{C}_{5} \mathrm{H}_{12}$ to present large, clear, colorless plates. Yield $94 \%$; m.p. $124-125^{\circ} \mathrm{C}$ (dec.); ${ }^{1} \mathrm{H}$ NMR $\left(\mathrm{C}_{6} \mathrm{D}_{6}\right): \delta 0.48(\mathrm{~m}, 1 \mathrm{H}) ; 1.25$ $(\mathrm{m}, 1 \mathrm{H}) ; 1.34(\mathrm{~s}, 9 \mathrm{H}) ; 1.58(\mathrm{~s}, 3 \mathrm{H}) ; 1,64(\mathrm{~m}, 3 \mathrm{H}) 2.29(\mathrm{~m}$, 1H); $2.75(\mathrm{~m}, 1 \mathrm{H}) ; 3.01(\mathrm{~m}, 1 \mathrm{H}) ; 5.22(\mathrm{~s}, 1 \mathrm{H}) .{ }^{13} \mathrm{C} \mathrm{NMR}$ $\left(\mathrm{C}_{6} \mathrm{D}_{6}\right): \delta 11.5 ; 21.7 ; 26.2 ; 28.6 ; 39.1 ; 49.4 ; 94.7 ; 172.0 ; 188.9$ Anal. Calc. for $\mathrm{C}_{21} \mathrm{H}_{37} \mathrm{~N}_{2} \mathrm{O}_{2} \mathrm{Al}$ : C, 66.99; H, 9.90; N, 7.44. Found: C, 66.56; H, 9.76; N, 7.39\%.

\subsection{Polymeriation of racemic lactide}

Two $25 \mathrm{~mL}$ Schlenk flasks under $\mathrm{N}_{2}$ were each charged with $720 \mathrm{mg}$ ( $5.0 \mathrm{mmol}$ ) rac-lactide, $10 \mathrm{~mL}$ toluene, and a stir bar. To one, $0.2 \mathrm{~mL}$ of $\mathrm{MeOH}$ was added and both flasks heated to $70^{\circ} \mathrm{C}$ until the rac-lactide dissolved. Following this $0.0188 \mathrm{~g}(0.05 \mathrm{mmol})$ of 3 was added to 
Table 1. Crystal data and structure refinement for 2 and 3

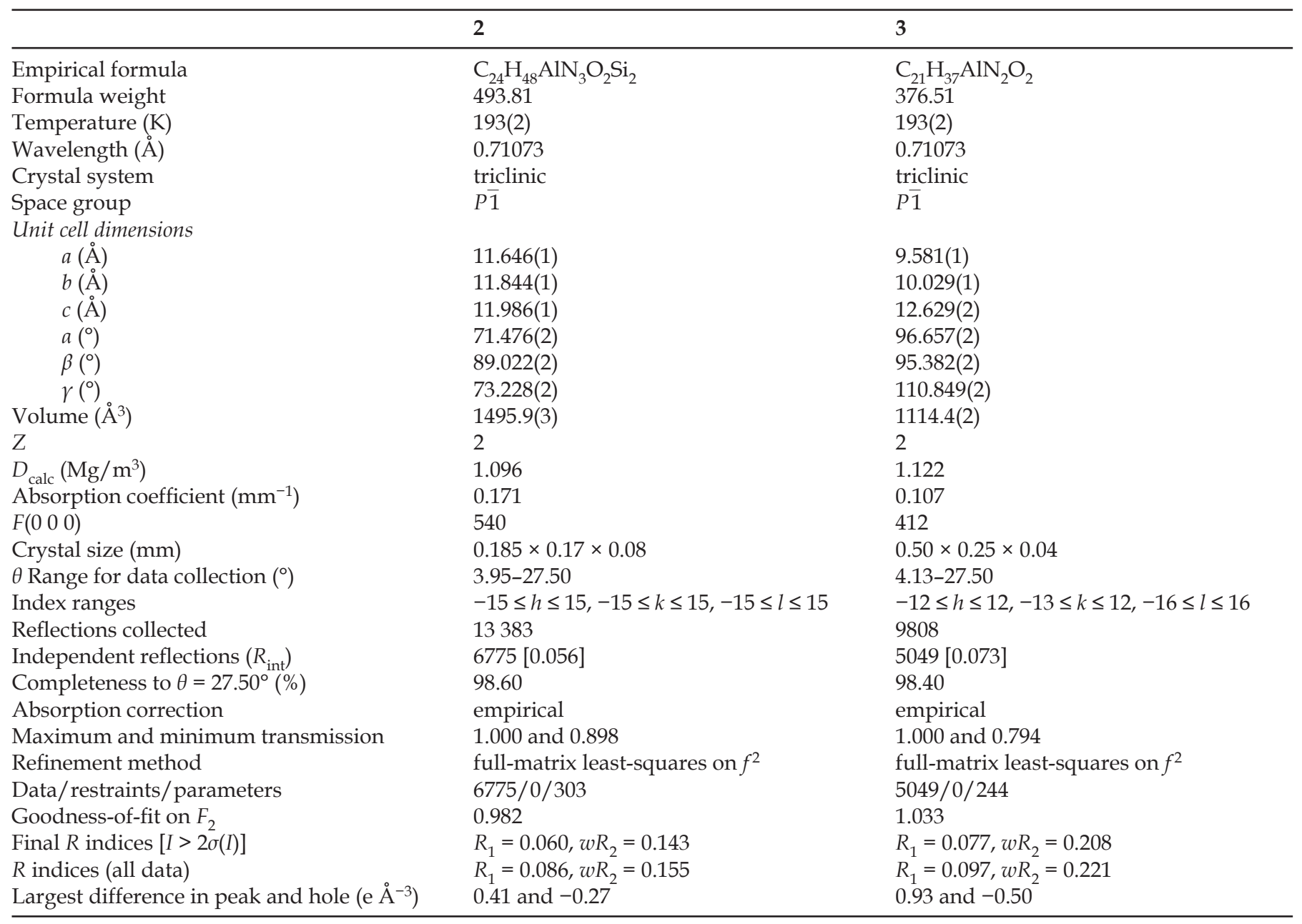

each as a $0.05 \mathrm{M}$ toluene solution. The reaction flasks remained immersed in an oil bath heated to $70^{\circ} \mathrm{C}$ and polymerization progress monitored by ${ }^{1} \mathrm{H}$ NMR. Near completion ( $\sim 90 \%$ conversion by disappearance of monomer) each flask containing polymer and catalyst were precipitated and quenched with $\mathrm{MeOH}$, respectively and dried in vacuo.

\section{Results and discussion}

\subsection{Ligands}

Organic 1 originates from a non-commercial diketone and the large frontal ${ }^{t} \mathrm{Bu}$ groups afford only one of three possible structural isomers following the Schiff-base condensation. A noteworthy and requisite ketoiminate purification step is a benzene azeotrope to remove all spurious $\mathrm{H}_{2} \mathrm{O}$ (the reaction byproduct), as anhydrous starting materials are essential or metallation will fail. Overall, ligand choice was predicated by our previous successes in isolating and structurally characterizing anhydrous, 5-coordinate Schiff-base lanthanide (III) complexes that all exhibited mononuclear, slightly distorted square pyramidal metal coordination geometry (vide supra). Since the metal coordination in $\left(\mathrm{C}_{2} \mathrm{H}_{5}\right) \mathrm{Al}\left(\mathrm{sal}_{2} \mathrm{en}\right)$ was reported to also be distorted square-pyramidal [1], we (incorrectly) anticipated a distorted square-pyramidal coordination for the $\mathrm{Al}^{3+}$ ion in 2 and 3 [12]. With the ligand set in 2 being nearly identical to that in some of our earlier studies with lanthanide(III) complexes, a structural characterization of $\mathbf{2}$ would allow us to assess the effects of reducing metal size on coordination geometry. Structural comparisons of $\mathbf{2}$ with $\mathbf{3}$, would also allow us to explore the extent to which changes in steric factors of the ligand set can effect metal coordination geometry: The SB in 3 has one more methylene group and the terminally-bonded ligand is considerably less bulky.

\subsection{Complexes}

$\mathrm{Al}^{3+}$ introduction occurs using commercial $\mathrm{Et}_{3} \mathrm{Al}$ solution or $\mathrm{Al}\left(\mathrm{N}[\mathrm{TMS}]_{2}\right)_{3}$ [13], the latter was synthesized and purified using literature preparations [11]. Addition of either to a heptane solution of the protio Schiff-base briefly causes a light-yellow color and then the reactions return to their transparent, colorless appearance. With $\mathrm{Et}_{3} \mathrm{Al}$, evolution of $\mathrm{C}_{2} \mathrm{H}_{6}$ is rapid and obvious (as evidenced by bubbling of the isolated the Schlenk $\mathrm{N}_{2}$ bubbler), whereas for bulkier $\mathrm{Al}\left(\mathrm{N}[\mathrm{TMS}]_{2}\right)_{3}$ steric factors slow the acid-base reaction. To assure completion, both 
Table 2. Selected bond lengths $(\AA)$ and angles $\left(^{\circ}\right)$ for compounds 2 and 3

\begin{tabular}{lrlr}
\hline $\mathbf{2}$ & \multicolumn{3}{c}{3} \\
\hline $\mathrm{Al}-\mathrm{O}(1)$ & $1.842(2)$ & $\mathrm{Al}-\mathrm{O}(1)$ & $1.868(2)$ \\
$\mathrm{Al}-\mathrm{O}(2)$ & $1.813(2)$ & $\mathrm{Al}-\mathrm{O}(2)$ & $1.802(2)$ \\
$\mathrm{Al}-\mathrm{N}(1)$ & $1.974(2)$ & $\mathrm{Al}-\mathrm{N}(1)$ & $1.954(2)$ \\
$\mathrm{Al}-\mathrm{N}(2)$ & $2.005(2)$ & $\mathrm{Al}-\mathrm{N}(2)$ & $2.060(2)$ \\
$\mathrm{Al}-\mathrm{N}(3)$ & $1.861(2)$ & $\mathrm{Al}-\mathrm{C}(21)$ & $1.984(3)$ \\
$\mathrm{C}(2)-\mathrm{C}(3)$ & $1.376(4)$ & $\mathrm{C}(2)-\mathrm{C}(3)$ & $1.377(4)$ \\
$\mathrm{C}(3)-\mathrm{C}(4)$ & $1.420(4)$ & $\mathrm{C}(3)-\mathrm{C}(4)$ & $1.413(4)$ \\
$\mathrm{C}(7)-\mathrm{C}(8)$ & $1.432(3)$ & $\mathrm{C}(8)-\mathrm{C}(9)$ & $1.432(4)$ \\
$\mathrm{C}(8)-\mathrm{C}(9)$ & $1.363(3)$ & $\mathrm{C}(9)-\mathrm{C}(10)$ & $1.363(3)$ \\
& & & \\
$\mathrm{O}(2)-\mathrm{Al}-\mathrm{O}(1)$ & $87.90(7)$ & $\mathrm{O}(2)-\mathrm{Al}-\mathrm{O}(1)$ & $87.78(8)$ \\
$\mathrm{O}(2)-\mathrm{Al}-\mathrm{N}(3)$ & $122.44(8)$ & $\mathrm{O}(2)-\mathrm{Al}-\mathrm{N}(1)$ & $113.21(9)$ \\
$\mathrm{O}(1)-\mathrm{Al}-\mathrm{N}(3)$ & $99.28(8)$ & $\mathrm{O}(1)-\mathrm{Al}-\mathrm{N}(1)$ & $88.10(9)$ \\
$\mathrm{O}(2)-\mathrm{Al}-\mathrm{N}(1)$ & $123.71(8)$ & $\mathrm{O}(2)-\mathrm{Al}-\mathrm{C}(21)$ & $119.88(13)$ \\
$\mathrm{O}(1)-\mathrm{Al}-\mathrm{N}(1)$ & $89.30(8)$ & $\mathrm{O}(1)-\mathrm{Al}-\mathrm{C}(21)$ & $93.22(10)$ \\
$\mathrm{N}(3)-\mathrm{Al}-\mathrm{N}(1)$ & $113.48(8)$ & $\mathrm{N}(1)-\mathrm{Al}-\mathrm{C}(21)$ & $126.90(13)$ \\
$\mathrm{O}(2)-\mathrm{Al}-\mathrm{N}(2)$ & $87.74(7)$ & $\mathrm{O}(2)-\mathrm{Al}-\mathrm{N}(2)$ & $88.48(9)$ \\
$\mathrm{O}(1)-\mathrm{Al}-\mathrm{N}(2)$ & $162.42(8)$ & $\mathrm{O}(1)-\mathrm{Al}-\mathrm{N}(2)$ & $173.63(8)$ \\
$\mathrm{N}(3)-\mathrm{Al}-\mathrm{N}(2)$ & $97.44(8)$ & $\mathrm{N}(1)-\mathrm{Al}-\mathrm{N}(2)$ & $88.65(9)$ \\
$\mathrm{N}(1)-\mathrm{Al}-\mathrm{N}(2)$ & $79.03(8)$ & $\mathrm{C}(21)-\mathrm{Al}-\mathrm{N}(2)$ & $93.11(10)$ \\
\end{tabular}

reactions were heated overnight at reflux. Once purified by recrystallization in $\mathrm{C}_{5} \mathrm{H}_{12}$ the colorless compounds exhibit melting points proportional to increased monoanion molecular dissymmetry and molecular weight (i.e. m.p. $2>3$ ), and each decomposes before volatilizing at $<10^{-5}$ Torr. There is no spectroscopic (NMR) or structural evidence to support complex dimerization or oligomerization [1, 2], and the lack of ligand aromaticity promotes the formation of mononuclear species in both solution and the solid-state [14-16], although fluxional behavior is suggested by the methylene proton splittings.

The X-ray diffraction-derived molecular structures of $\mathbf{2}$ and $\mathbf{3}$ are shown in Figure 2. Both compounds contain a 5-coordinate $\mathrm{Al}^{3+}$ ion that is terminallybonded to a monoanion and complexed to all four donor atoms of an $\mathrm{N}_{2} \mathrm{O}_{2}$ Schiff-base (Table 2). While the bis(trimethylsilyl)amino monoanion [16] in $\mathbf{2}$ is considerably bulkier than the ethyl monoanion in 3 , the eth- ylene bridged Schiff-base in $\mathbf{2}$ is slightly more compact and more restricted than the propylene-bridged $\mathrm{N}_{2} \mathrm{O}_{2}$ Schiff-base of 3 . The $\mathrm{Al}^{3+}$ coordination geometry in both complexes is best described as trigonal bipyramidal with a distorted polyhedron $(\tau=0.65)$ in 2 and a nearly ideal polyhedron $(\tau=1.00)$ in 3 [12]. Axial atoms $\mathrm{O}(1)$ and $N(2)$ subtend angles of $162.4(1)^{\circ}$ and $173.6(1)^{\circ}$ in 2 and 3 , respectively. The less ideal trigonal bipyramidal coordination geometry in $\mathbf{2}$ probably results from the smaller "bite" angle and increased rigidity attributable to its ethylene spacer as well as the increased bulk of its terminally-bonded anion when compared to 3 . This anion $\mathrm{Al}-\mathrm{N}(3)$ bond length of $1.86 \AA$ is one of the shortest "apical" bond lengths amongst this class of compounds, and more closely resemble that of the hindered organometallic imido $\mathrm{Cp}^{*} \mathrm{AlNSiPh}_{3}$ [1] and [17]. The wrapping pattern adopted by the Schiff-base in both complexes is the one expected: it spans 3 contiguous polyhedral edges that would ideally subtend a $90^{\circ}$ angle at the metal. Furthermore, the SB Al-O and Al-N distances in $\mathbf{2}$ and $\mathbf{3}$ all exhibit the sterically-anticipated trigonal-bipyramidal trend of longer bonds to axial ligands than to equatorial ligands. Interestingly, these differences in $\mathrm{SB} \mathrm{Al-O}$ and $\mathrm{Al}-\mathrm{N}$ distances are considerably larger for the nearly ideal 3 (0.066-0.106 $\AA$ ) than the more distorted 2 (0.029$0.031 \AA)$. The $\mathrm{C}-\mathrm{C}$ bond lengths within the ketoiminato rings $[C(2)-C(3)<C(3)-C(4), C(8)-C(9)<C(7)-C(8)$ in 2 and $C(2)-C(3)<C(3)-C(4), C(9)-C(10)<C(8)-C(9)$ in 3] suggest more enolic character [3] with the primary resonance structure favoring the harder oxygen atoms upon chelation in both complexes. The remaining $\mathrm{C}-\mathrm{O}, \mathrm{C}-\mathrm{N}$ and $\mathrm{C}-\mathrm{C}$ bond lengths in $\mathbf{2}$ and $\mathbf{3}$ are unremarkable.

While complex 2 contains a terminally-bonded bis(trimethylsilyl)amido group and an ethylene-bridged Schiff-base, organometallic complex 3 has a terminallybonded ethyl group and a propyl-bridged Schiff-base [1, 16]. The equatorial plane has a slight deformation [12] with $\mathrm{C}(21)$ canted from an idealized $\mathrm{N}_{2} \mathrm{O}_{2}$ normal although equally centered between $\mathrm{N}(2)$ and $\mathrm{O}(1)$. It resides forward toward $\mathrm{O}(2)$ and the $\mathrm{C}(21)-\mathrm{Al}-\mathrm{O}(2)$ and
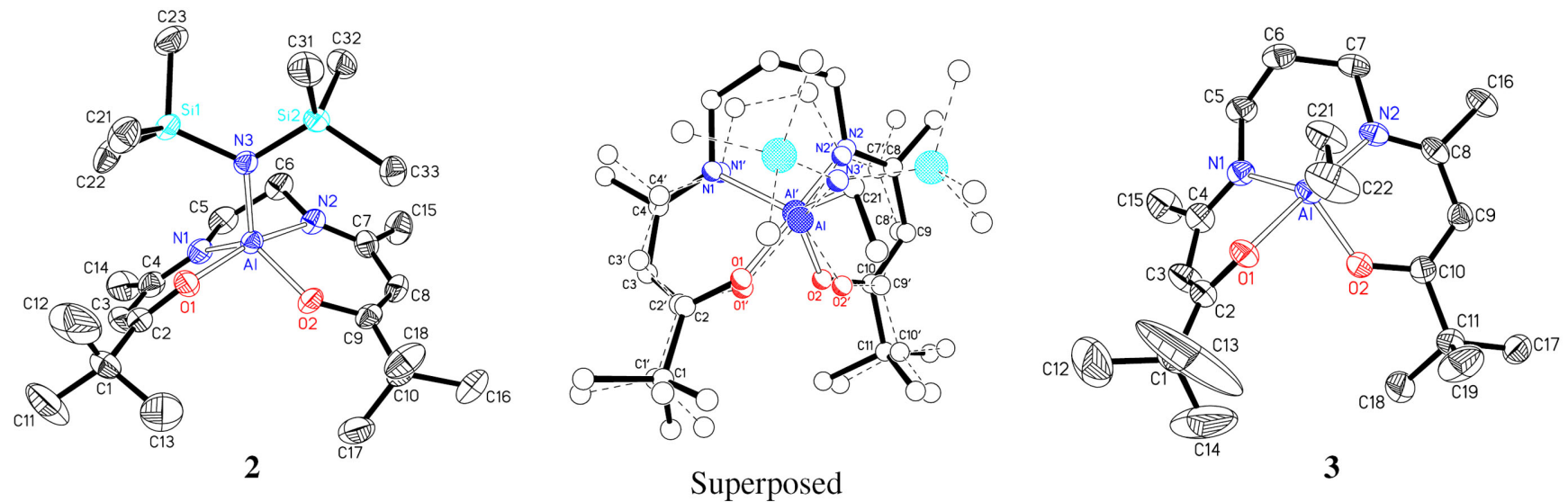

Figure 2. X-ray diffraction-derived molecular structures of $\mathbf{2}$ and $\mathbf{3}$ and each coordination environment superposed. Relevant bond lengths and angles can be found in Table 2 and discussions throughout the text. Hydrogen atoms were removed for clarity and thermal ellipsoids are at $30 \%$ probability. 
$\mathrm{C}(21)-\mathrm{Al}-\mathrm{N}(1)$ angles are $119.9^{\circ}$ and $126.9^{\circ}$, respectively. This distortion is most likely due to the frontal steric constraints forming an unsymmetric pocket above one of the ${ }^{t} \mathrm{Bu}$ groups and removal of the eclipsed hydrogen conformation along the methylenes of the larger $\mathrm{C}_{3}$ linker [1]. This $\mathrm{C}_{3}$ backbone of the propyl bridge in 3 forms a six-membered chelate ring, $\mathrm{Al}-\mathrm{N}(1)-\mathrm{C}(6)-\mathrm{C}(7)-$ $\mathrm{C}(8)-\mathrm{N}(2)$, that adopts the boat conformation. Figure 2 also shows a superposition of $\mathbf{2}$ and 3 . The labeled atoms from the ketoiminato halves, the coordinated atoms from the monodentate ligands, and the exocyclic carbons have an rms deviation of $0.283 \AA$ and a maximum deviation of $0.482 \AA$. One of the Schiff-base ${ }^{t} \mathrm{Bu}$ groups in each molecule also superimposes quite closely. The regions where the two Schiff-bases in $\mathbf{2}$ and $\mathbf{3}$ do not superimpose are near the linker groups and the second ${ }^{t} \mathrm{Bu}$ group which is rotated about the $\mathrm{C}(1)-\mathrm{C}(2)$ bond in 2 relative to 3 . Although the ligand set in $\mathbf{2}$ is virtually identical (with the exception of one less methylene group in the linker) to that for the earlier trivalent lanthanide complexes [9], the ionic radius of 5-coordinate $\mathrm{Al}^{3+}$ is smaller. The net result of replacing a trivalent lanthanide ion with the smaller $\mathrm{Al}^{3+}$ ion is therefore to "pull" all of the ligands radially toward the central metal ion. This produces shorter intraligand contacts unless the relative orientations of the ligands change. A minor reorientation (linked-ligand Berry pseudo-rotation) of the square-pyramidal lanthanide amido/Schiff-base ligand set would give distorted trigonal bipyramidal $\mathrm{Al}^{3+}$ coordination in $\mathbf{2}$ with shorter metal-ligand distances.

Lactide polymerizations to produce polylactic acid (pLA) are an intensely active area within green chemistry. Inspired by Nomura and others using Al Salen complexes [4-7] we began evaluating our "saturated" complexes as polymerization catalysts for this biocompatible material. Initially, $\mathbf{2}$ and $\mathbf{3}$ were used to initiate polymerization, however no activity was observed with 2 and only modest turnovers with 3 . Furthermore, polymers derived from 3 exhibited low molecular weights, broad polydispersities, and no stereocontrol. Following these efforts, and anticipating that the apical ligand and metal center were too encumbered with peripheral steric bulk to allow monomer insertion, we began activating the Al Schiff-base complexes with methanol and benzyl alcohol. Although our efforts are only beginning, using the aforementioned systems (with various loadings) we have recovered atactic pLA with molecular weight control (up to 20,000 Da) and monomodal polydispersities $(<1.3)$. Currently, we are optimizing reaction conditions, performing more detailed mechanistic studies, and attempting to control tacticity [6].

\section{Conclusions}

This report presents our initial results on a new organic Schiff-base (1) and the molecular structures of two new
$\mathrm{Al}^{3+}$ complexes bearing "saturated" Schiff-bases ( 2 and 3). Unlike the square pyramidal geometry of their isoelectronic rare earth congeners, both aluminum complexes adopt ideal and slightly distorted trigonal bipyramidal coordination environments. Initial polymerization results with either the terminal ethyl or bis(trimethylsilyl)amino ligand failed; however, activation with trace $\mathrm{MeOH}$ yielded biodegradable polymers with some control over both molecular weights and polydispersity.

\section{Acknowledgments}

This work was supported by the Nebraska Research Initiative. J.A.B. also thanks Steve A. Schuetz for early explorations into this project.

\section{References}

[1] D. A. Atwood and M. J. Harvey, Chem. Rev. 101 (2001), p. 37.

[2] V. C. Gibson and S. K. Spitzmesser, Chem. Rev. 103 (2003), p. 283.

[3] H. Sugimoto, H. Ohtsuka and S. Inoue, J. Polym. Sci. Part A: Polym. Chem. 43 (2005), p. 4172.

[4] Z. Tang, X. Chen, X. Pang, Y. Yang, X. Zhang and X. Jing, Biomacromolecules 5 (2004), p. 965.

[5] Z. Tang, X. Chen, Y. Yang, X. Pang, J. Sun, X. Zhang and X. Jing, J. Polym. Sci. Part A: Polym. Chem. 42 (2004), p. 5974.

[6] N. Nomura, R. Ishii, M. Akakura and K. Aoi, J. Am. Chem. Soc. 124 (2002), p. 5938.

[7] D. Jhurry, A. Bhaw-Luximon and N. Spassky, Macromol. Symp. 175 (2001), p. 67.

[8] J. Lewinski, J. Zachara, I. Justyniak and M. Dranka, Coord. Chem. Rev. 249 (2005), p. 1185.

[9] S. A. Schuetz, C. M. Silvernail, C. D. Incarvito, A. L. Rheingold, J. L. Clark, V. W. Day and J. A. Belot, Inorg. Chem. 43 (2004), p. 6203 and references therein.

[10] J. T. Adams and C. R. Hauser, J. Am. Chem. Soc. 66 (1944), p. 1220.

[11] P. J. Brothers, R. J. Wehmschulte, M. M. Olmstead, K. Ruhlandt-Senge, S. R. Parkin and P. P. Power, Organometallics 13 (1994), p. 2792.

[12] A. W. Addison, T. N. Rao, J. Reedijk, J. van Rijn and G. C. Verschoor, J. Chem. Soc. , Dalton Trans. (1984), p. 1349.

[13] A. K. Jain, A. Gupta, R. Bohra, I. -P. Lorenz and P. Mayer, Polyhedron 25 (2006), p. 654.

[14] Q. Liu and M. Ding, J. Organomet. Chem. 553 (1998), p. 179.

[15] Q. Liu, M. Ding, Y. Lin and Y. Xing, J. Organaomet. Chem. 548 (1997), p. 139.

[16] S. J. Dzugan, V. L. Goedken Inorg. Chem. 25 (1986), p. 2858.

[17] M.-A. Munoz-Hernandez, T. S. Keizer, P. Wei, S. Parkin and D. A. Atwood, Inorg. Chem. 40 (2001), p. 6782.

[ Appendix A. Supporting Information follows ] 


\section{Appendix A. Supporting Information}

\section{X-ray experimental for compound 2 (CCDC \#624040)}

Colorless crystals of $\left[\left(\mathrm{N}_{2} \mathrm{O}_{2} \mathrm{C}_{18} \mathrm{H}_{30}\right)\right] \mathrm{Al}\left[\mathrm{N}\left(\mathrm{Si}\left(\mathrm{CH}_{3}\right)_{3}\right)_{2}\right]$ are, at $193(2) \mathrm{K}$, triclinic, space group $\mathrm{P} \overline{1}-\mathrm{C}_{\mathrm{i}}{ }^{1}$ (No. 2) (1) with $\mathbf{a}=11.646(1) \AA, \mathbf{b}=11.844(1) \AA, \mathbf{c}=11.986(1) \AA, \boldsymbol{\alpha}=71.476(2)^{\circ}, \boldsymbol{\beta}=$ $89.022(2)^{\circ}, \boldsymbol{\gamma}=73.228(2)^{\circ}, \mathrm{V}=1495.9(3) \AA^{3}$ and $\mathrm{Z}=2$ molecules $\left\{\mathrm{d}_{\text {calcd }}=1.096 \mathrm{~g} / \mathrm{cm}^{3} ; \mu_{\mathrm{a}}(\mathrm{MoK} \alpha)\right.$ $\left.=0.17 \mathrm{~mm}^{-1}\right\}$. A full hemisphere of diffracted intensities (1868 10 -second frames with a $\omega$ scan width of $0.30^{\circ}$ ) was measured for a single-domain specimen using graphite-monochromated MoK $\alpha$ radiation $(\lambda=0.71073 \AA)$ on a Bruker SMART APEX CCD Single Crystal Diffraction System (2). $\mathrm{X}$-rays were provided by a fine-focus sealed $\mathrm{x}$-ray tube operated at $50 \mathrm{kV}$ and $30 \mathrm{~mA}$. Lattice constants were determined with the Bruker SAINT software package using peak centers for 1917 reflections. A total of 13383 integrated reflection intensities having $2 \theta(\mathrm{MoK} \alpha)<55.00^{\circ}$ were produced using the Bruker program SAINT(3); 6775 of these were unique and gave $\mathrm{R}_{\text {int }}=0.056$ with a coverage which was $98.6 \%$ complete. The data were corrected empirically for variable absorption effects using 530 equivalent reflections; the relative transmission factors ranged from 0.898 to 1.000 . The Bruker software package SHELXTL was used to solve the structure using "direct methods" techniques. All stages of weighted full-matrix least-squares refinement were conducted using $\mathrm{F}_{\mathrm{o}}{ }^{2}$ data with the SHELXTL Version 6.10 software package(4).

The fourteen methyl groups were included in the structural model as rigid rotors (assuming idealized $\mathrm{sp}^{3}$-hybridization of the carbon and a C-H bond length of $0.98 \AA$ ) which were allowed to rotate about their Si-C or C-C bonds in least-squares refinement cycles. The remaining hydrogen atoms were included in the structural model as idealized atoms (assuming $\mathrm{sp}^{2}$ - or $\mathrm{sp}^{3}$-hybridization of the carbon atoms and $\mathrm{C}-\mathrm{H}$ bond lengths of $0.95-0.99 \AA$ ). The isotropic thermal parameters of all idealized hydrogen atoms were fixed at values 1.2 (nonmethyl) or 1.5 (methyl) times the equivalent isotropic thermal parameter of the carbon atom to which they are covalently bonded.

The final structural model incorporated anisotropic thermal parameters for all nonhydrogen atoms and isotropic thermal parameters for all hydrogen atoms. A total of 303 parameters were refined using no restraints, 6775 data and weights of $\mathrm{w}=1 /\left[\sigma^{2}\left(\mathrm{~F}^{2}\right)+(0.0747 \mathrm{P})^{2}\right]$, where $\mathrm{P}=\left[\mathrm{F}_{\mathrm{o}}+\right.$ $\left.2 \mathrm{~F}_{\mathrm{c}}{ }^{2}\right] / 3$. Final agreement factors at convergence are: $\mathrm{R}_{1}($ unweighted, based on $\mathrm{F})=0.060$ for 4862 independent absorption-corrected "observed" reflections having $2 \theta(\mathrm{MoK} \alpha)<55.00^{\circ}$ and $\mathrm{I}>2 \sigma(\mathrm{I})$; $\mathrm{R}_{1}$ (unweighted, based on $\mathrm{F}$ ) $=0.086$ and $\mathrm{wR}_{2}$ (weighted, based on $\mathrm{F}^{2}$ ) $=0.155$ for all 6775 independent absorption-corrected reflections having $2 \theta(\mathrm{MoK} \alpha)<55.00^{\circ}$. The largest shift/s.u. was 0.000 in the final refinement cycle. The final difference Fourier contained maxima and minima of $0.41 \mathrm{e}^{-} / \AA^{3}$ and $-0.27 \mathrm{e}^{-} / \AA^{3}$, respectively. 


\section{X-ray experimental for compound 3 (CCDC \#624041)}

Colorless crystals of $\left[\mathrm{N}_{2} \mathrm{O}_{2} \mathrm{C}_{19} \mathrm{H}_{32}\right] \mathrm{Al}\left[\mathrm{C}_{2} \mathrm{H}_{5}\right]$ are, at $193(2) \mathrm{K}$, triclinic, space group $\mathrm{P} \overline{1}-\mathrm{C}_{\mathrm{i}}{ }^{1}$

(No. 2) (1) with $\mathbf{a}=9.581(1) \AA, \mathbf{b}=10.029(1) \AA, \mathbf{c}=12.629(2) \AA, \boldsymbol{\alpha}=96.657(2)^{\circ}, \boldsymbol{\beta}=95.382(2)^{\circ}, \boldsymbol{\gamma}$ $=110.849(2)^{\circ}, \mathrm{V}=1114.4(2) \AA^{3}$ and $\mathrm{Z}=2$ molecules $\left\{\mathrm{d}_{\mathrm{calcd}}=1.122 \mathrm{~g} / \mathrm{cm}^{3} ; \mu_{\mathrm{a}}(\mathrm{MoK} \alpha)=0.11 \mathrm{~mm}^{-}\right.$

$\left.{ }^{1}\right\}$. A full hemisphere of diffracted intensities (1868 10-second frames with a $\omega$ scan width of $0.30^{\circ}$ ) was measured for a single-domain specimen using graphite-monochromated MoK $\alpha$ radiation $(\lambda=$ $0.71073 \AA$ ) on a Bruker SMART APEX CCD Single Crystal Diffraction System (2). X-rays were provided by a fine-focus sealed $\mathrm{x}$-ray tube operated at $50 \mathrm{kV}$ and $30 \mathrm{~mA}$. Lattice constants were determined with the Bruker SAINT software package using peak centers for 3132 reflections. A total of 9808 integrated reflection intensities having $2 \theta(\mathrm{MoK} \alpha)<55.00^{\circ}$ were produced using the Bruker program SAINT(3); 5049 of these were unique and gave $\mathrm{R}_{\text {int }}=0.073$ with a coverage which was 98.4\% complete. The data were corrected empirically for variable absorption effects using 1415 equivalent reflections; the relative transmission factors ranged from 0.794 to1.000. The Bruker software package SHELXTL was used to solve the structure using "direct methods" techniques. All stages of weighted full-matrix least-squares refinement were conducted using $\mathrm{F}_{\mathrm{o}}{ }^{2}$ data with the SHELXTL Version 6.10 software package(4).

The nine methyl groups were included in the structural model as rigid rotors (assuming idealized $\mathrm{sp}^{3}$-hybridization of the carbon and a C-H bond length of $0.98 \AA$ ) which were allowed to rotate about their $\mathrm{C}-\mathrm{C}$ bonds in least-squares refinement cycles. The remaining hydrogen atoms were included in the structural model as idealized atoms (assuming $\mathrm{sp}^{2}$ - or $\mathrm{sp}^{3}$-hybridization of the carbon atoms and $\mathrm{C}-\mathrm{H}$ bond lengths of $0.95-0.99 \AA$ ). The isotropic thermal parameters of all idealized hydrogen atoms were fixed at values 1.2 (nonmethyl) or 1.5 (methyl) times the equivalent isotropic thermal parameter of the carbon atom to which they are covalently bonded.

The final structural model incorporated anisotropic thermal parameters for all nonhydrogen atoms and isotropic thermal parameters for all hydrogen atoms. A total of 244 parameters were refined using no restraints, 5049 data and weights of $\mathrm{w}=1 /\left[\sigma^{2}\left(\mathrm{~F}^{2}\right)+(0.1250 \mathrm{P})^{2}+0.4117 \mathrm{P}\right]$, where $\mathrm{P}=\left[\mathrm{F}_{\mathrm{o}}+2 \mathrm{~F}_{\mathrm{c}}{ }^{2}\right] / 3$. Final agreement factors at convergence are: $\mathrm{R}_{1}($ unweighted, based on $\mathrm{F})=0.077$ for 3751 independent absorption-corrected "observed" reflections having $2 \theta(\mathrm{MoK} \alpha)<55.00^{\circ}$ and $\mathrm{I}>2 \sigma(\mathrm{I}) ; \mathrm{R}_{1}$ (unweighted, based on $\left.\mathrm{F}\right)=0.097$ and $\mathrm{wR}_{2}\left(\right.$ weighted, based on $\mathrm{F}^{2}$ ) $=0.221$ for all 5049 independent absorption-corrected reflections having $2 \theta(\mathrm{MoK} \alpha)<55.00^{\circ}$. The largest shift/s.u. was 0.000 in the final refinement cycle. The final difference Fourier contained maxima and minima of 
$0.93 \mathrm{e}^{-} / \AA^{3}$ and $-0.50 \mathrm{e}^{-} / \AA^{3}$, respectively.

\section{References}

1. International Tables for Crystallography, Vol A, $4^{\text {th }}$ ed., Kluwer: Boston (1996).

2. Data Collection: SMART Software Reference Manual (1998). Bruker-AXS, 5465 E. Cheryl Parkway, Madison, WI 53711-5373 USA.

3. Data Reduction: SAINT Software Reference Manual (1998). Bruker-AXS, 6300 Enterprise Dr., Madison, WI 53719-1173, USA.

4. (a) G. M. Sheldrick (2000). SHELXTL Version 6.10 Reference Manual. Bruker-AXS,5465 E. Cheryl Parkway, Madison, WI 53711-5373 USA+ 